\title{
Review on polymer processing techniques using supercritical carbon dioxide $\left(\mathrm{scCO}_{2}\right)$
}

\author{
F. Nadeem* \\ Department of Chemistry, University of Agriculture, Faidalabad-38040-Pakistan \\ *Corresponding Author Email: farwa668@gmail.com
}

\begin{abstract}
Supercritical fluids (SCFs) are the materials formed at the values of temperature and pressure, above its critical point. Some supercritical fluids can replace the toxic industrial solvents. Unique properties of the supercritical fluids especially supercritical carbon dioxide $\left(\mathrm{scCO}_{2}\right)$ provide the various opportunities in the field of polymerization. The supercritical carbon dioxide $\left(\mathrm{scCO}_{2}\right)$ is used as a monomer, reaction medium and catalyst for the synthesis of polymers. Various processes for the polymer synthesis have been discussed in this review article such as homogeneous polymerization, step growth polymerization, emission polymerization, dispersion polymerization and electrochemical synthesis of conducting polymers. The polymers can be readily separated from the reaction mixture as the particles or drops, in the presence of supercritical carbon dioxide $\left(\mathrm{scCO}_{2}\right)$ during the polymerization. In this review, some applications including impregnation and supercritical dyeing, purification of polymers, polymer modifications and particle production has been evaluated to study the efficiency of super critical fluids on the polymer production. This article also demonstrates the effects of various parameters on the process of polymerization such as $\mathrm{pH}$, temperature and pressure. Generally, by increasing the values of $\mathrm{pH}$ or the reaction media, the viscosity of prepared polymers tends to increase. The characterization techniques such as Fourier Transform Infrared (FTIR) spectroscopy, X-Ray Diffraction (XRD), ${ }^{1} \mathrm{H}$ Nuclear Magnetic Resonance $\left({ }^{1} \mathrm{HNMR}\right)$ and Differential Scanning Calorimetry (DSC) are also discussed for the determination of chemical arrangement, structure of polymers and functional groups.
\end{abstract}

Keywords: supercritical carbon dioxide $\left(\mathrm{scCO}_{2}\right)$, polymer, FTIR, XRD, ${ }^{1} \mathrm{HNMR}$, DSC

\section{INTRODUCTION}

Polymers are the macromolecules having subunits of monomers that react to form the three-dimensional (3D) structures or long chains [1]. In the past few decades, some polymers have become the necessary part of our daily life. Their feasible production and processing are essential for numerous applications. Polymer (foams, nanoparticles, and microparticles) formation is highly valuable for the drug release applications. Instead of using the conventional solvents for the polymer synthesis, recent research has been shifted to the use of supercritical fluids. In the polymer industry, supercritical fluids can be used for a variety of processes, for example as solvents in polymer synthesis, as plasticising agents or for the chemical recycling. The polymers and their applications comprise many active areas of the research for the "supercritical fluids based technologies" which experienced the exponential growth since about 1990 [2].

A fluid is called supercritical when its pressure and temperature exceed the critical pressure $\left(\mathrm{P}_{c}\right)$ and temperature $\left(\mathrm{T}_{c}\right)$. The supercritical fluids have a unique combination of density (like liquid) and viscosity (like gas). At that critical point, the interface between liquid and gas disappears and it makes the supercritical fluid an excellent solvent [3]. These types of fluids can also be considered as the "green solvents of future" mainly because of their low energy utilization and relatively high ecological benefits. The existence of supercritical water $\left(\mathrm{scH}_{2} \mathrm{O}\right)$ is evident in the areas close to the extreme volcanic eruptions. These two solvents (i) supercritical carbon dioxide $\left(\mathrm{scCO}_{2}\right)$ and (ii) supercritical water $\left(\mathrm{scH}_{2} \mathrm{O}\right)$ are the most commonly used solvents so far. Both these solvents are non-mutagenic, non-flammable, noncarcinogenic, non-toxic and thermodynamically very stable in nature. The supercritical fluids are known to have the number of applications in industrial scale food processing units, pharmaceutical industries, textile units and huge chemical industries. They are used as a reaction media or reactants and processing solvents. Processes with these fluids are eco-friendly, sustainable, and cost efficient, and they also offer many possibilities to form the new products with the special customer designed properties [4].

The supercritical carbon dioxide $\left(\mathrm{scCO}_{2}\right)$ is known to be the best substitute for the large number of noxious organic solvents and various chlorofluorocarbons (CFCs) for being non-toxic in nature. These types of solvents can also be used in the production of polymer because of their unique physiochemical properties such as cheapness, non-flammability and high inertness. The super critical conditions of the supercritical carbon dioxide $\left(\mathrm{scCO}_{2}\right)$ can easily be achieved $(\mathrm{Pc}=7.38 \mathrm{MPa}$ and $\mathrm{Tc}=304 \mathrm{~K})$, and further it can easily be extracted from the reaction media after being used, with the help of simple depressurizing process. The increased quality and relatively high yield of final product draw the attention of scientists and researchers towards the excessive use of supercritical carbon dioxide $\left(\mathrm{scCO}_{2}\right)$. In these types of systems, mixture of solvents can be used to enhance the speed and efficiency of a chemical reaction, during the entire process of synthesis of polymers [5]. The process of polymerization using the supercritical carbon dioxide $\left(\mathrm{scCO}_{2}\right)$ is economically favourable and practically feasible as supercritical carbon dioxide $\left(\mathrm{scCO}_{2}\right)$ can easily be separated from the reaction mixture in the form of liquid droplets. Therefore, as a result of this process, the viscosity of most of the chemical processes tends to be relatively low and smooth mixing is favoured. In the use of supercritical carbon dioxide $\left(\mathrm{scCO}_{2}\right)$, 
the environmental problems like (i) toxic nature of volatile organic solvents and (ii) pressure dependant unique physiochemical properties such as diffusibility, density and viscosity, have also been resolved upto great extent [6].

In this review, some methods for the synthesis of polymers using supercritical carbon dioxide $\left(\mathrm{scCO}_{2}\right)$ from their environmental aspects, product quality and energy are discussed such as step growth polymerization, homogeneous polymerization, dispersion polymerization and emulsion polymerization. This review highlights the various applications of supercritical carbon dioxide $\left(\mathrm{scCO}_{2}\right)$ in the polymer processing field. Some advanced analytical techniques such as ${ }^{1} \mathrm{H}$ Nuclear Magnetic Resonance ( ${ }^{1} \mathrm{H}$ NMR) spectroscopy, Differential Scanning Calorimetry (DSC), Fourier Transform Infrared (FTIR) spectroscopy and X-Ray Diffraction Technique (XRD) have also been evaluated.

\subsection{SUPERCRITICAL FLUIDS (SCFs)}

The supercritical fluids are the form of a physical state of matter at which various organic and inorganic compounds can attain the certain critical parameters such as pressure and temperature. The critical temperature $\left(T_{c}\right)$ is the temperature of any substance at and above which the vapours of substance cannot be liquefied by any pressure alone. The critical pressure $\left(\mathrm{P}_{\mathrm{c}}\right)$ is a minimum pressure required to change the pure form of any substance into its supercritical form. The compound does not decompose at their critical temperature. After the critical point is achieved, the phase boundary between liquid and gas disappears [2]. Gas and liquid like properties, solvating properties of the fluids and dielectric constant can be controlled by the pressure and temperature. Due to these properties, they can be used as excellent solvents for various applications [3]. Moreover, SCFs have good properties of heat transfer and applied as the heat transfer fluids because they have no bad impact on the environment as compared to the various other conventional processes which are toxic and also discharge potential greenhouse gases (GHGs) [7]. The procedures with the supercritical carbon dioxide $\left(\mathrm{scCO}_{2}\right)$ are very eco-friendly, non-toxic, and cost-efficient in nature. They can also be used for the polymerization and other industrial processes to obtain the new products. The phase diagram of the super critical fluids is shown in the graph below (Fig 1.).

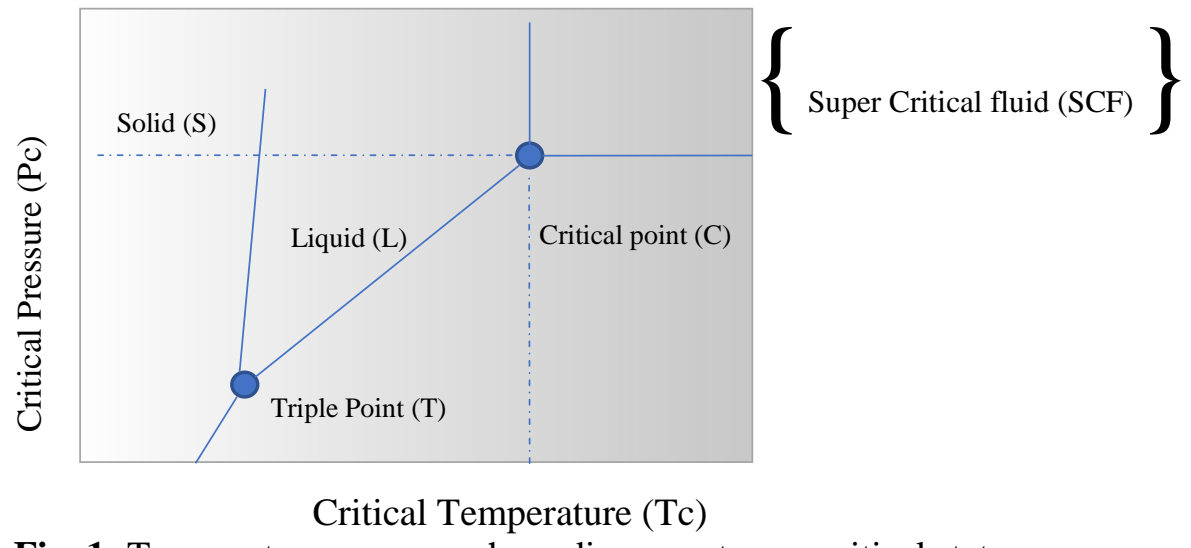

Fig. 1: Temperature pressure phase diagram at supercritical state

The Fig. 1 shows a schematic representation of temperature-pressure phase diagram for the pure component as it is surrounded by the triple point $(\mathrm{T})$ and critical point $(\mathrm{C})$. The supercritical fluids are considered to be a potential alternative to the organic solvents mainly due to their unique physical characteristics and peculiar chemical properties. The carbon dioxides and water are among the super critical inorganic fluids (supercritical carbon dioxide $\left(\mathrm{scCO}_{2}\right)$ and supercritical water $\left(\mathrm{scH}_{2} \mathrm{O}\right)$ most widely used for the preparation of large number of organic compounds and inorganic substances [8].

\subsubsection{Supercritical carbon dioxide}

The carbon dioxide $\left(\mathrm{CO}_{2}\right)$ is known to have relatively low critical parameters such as critical temperature $\left(\mathrm{T}_{\mathrm{c}}\right) 31^{\circ} \mathrm{C}$ and critical pressure $\left(\mathrm{P}_{\mathrm{c}}\right) 7.38 \mathrm{MPa}$ and $\rho_{\mathrm{c}}=0.468 \mathrm{~g} / \mathrm{cm}^{3}$. The supercritical carbon dioxide $\left(\mathrm{scCO}_{2}\right)$ is non-toxic, nonexplosive, non-flammable, easily available and cheap source of energy. Therefore, it is most commonly used as the reaction medium, catalyst of organic reactions, solvent of organic synthesis and for the extraction of both natural raw materials of animals and plants [9]. The polymer based chemistry offers the most promising applications of supercritical carbon dioxide $\left(\mathrm{scCO}_{2}\right)$ due to its ability to dissolve the large number of organic compounds. It is also prerequisite for the synthesis of large number of industrially valuable polymeric compounds [8]. The supercritical carbon dioxide $\left(\mathrm{scCO}_{2}\right)$ as a green solvent, can also be used in the polymer synthesis, processing aspects and applications that are now appearing as a growing area for the industrial processes [10]. 
The supercritical carbon dioxide $\left(\mathrm{scCO}_{2}\right)$ is known to have high dissolution potential and highly inert nature towards most of the monomeric molecules, due to the (i) high diffusion coefficient almost 100 times higher than the regular liquids and (ii) relatively low viscosity, almost 10 to 100 times less than the common fluids. The supercritical carbon dioxide $\left(\mathrm{scCO}_{2}\right)$ can easily be removed without leaving any residual material from the reaction mixture, after the completion of synthesis. The supercritical carbon dioxide $\left(\mathrm{scCO}_{2}\right)$ can also be recycled again and again. During the polymerization reaction, the supercritical carbon dioxide $\left(\mathrm{scCO}_{2}\right)$ does not pose any serious threat to the chain transfer and chain termination process of the polymers. Due to the higher rates of diffusion, the supercritical carbon dioxide $\left(\mathrm{scCO}_{2}\right)$ also makes it possible to carry out the large number of post purification processes of the complex polymeric products from the simpler residual monomers and initiator molecules. The washing of resulting polymers, using the fresh fluid solution is ultimately required to enhance the purity of final product. These types of useful applications of supercritical carbon dioxide $\left(\mathrm{scCO}_{2}\right)$ ensures its excessive usage in polymer chemistry and industrial processes [8].

The supercritical carbon dioxide $\left(\mathrm{scCO}_{2}\right)$ facilitates as a non-solvating power which also acts as an organic diluent. The carbon dioxide usually does not interact with any of the strong nucleophiles such as alkoxides and primary amines. Therefore, the polymerization through supercritical carbon dioxide $\left(\mathrm{scCO}_{2}\right)$ is suggested through the anionic mechanism. The supercritical carbon dioxide $\left(\mathrm{scCO}_{2}\right)$ can alter the glass transition temperature $\left(\mathrm{T}_{\mathrm{g}}\right)$ of polymers which leads to their reduced viscosity. By using the supercritical carbon dioxide $\left(\mathrm{scCO}_{2}\right)$, the dry polymers can be easily prepared by only depressurizing the reactor, after the polymerization [11].

\subsection{POLYMERIZATION}

The synthesis of polymers in the supercritical carbon dioxide $\left(\mathrm{scCO}_{2}\right)$ is an area of research that is intensively developed during the last few decades. Many monomers are soluble in this medium and the solubility of polymers in it, substantially increased at the $p>50 \mathrm{MPa}$ [12]. When the chains of polymer attain their threshold length, it become immiscible in the medium followed by the separation of phase, leading to the stabilization of polymeric particles with the dispersant present in that system. The polymers of higher molecular weight are often produced by using the higher conversion ratios and improved the reaction kinetics. Low solubility of the polymers in the supercritical carbon dioxide $\left(\mathrm{scCO}_{2}\right)$ cannot inhibit the conduction of polymerizations in the supercritical carbon dioxide $\left(\mathrm{scCO}_{2}\right)$ medium. As in the dispersion polymerizations, presence of the added stabilizers in the final polymer product can be tolerated. Through this procedure, the faster and higher conversions of the monomers to the polymers with the high molecular weight can be obtained [13]. Traditionally, many polymerizations in the supercritical carbon dioxide $\left(\mathrm{scCO}_{2}\right)$ can be carried out by the step growth polymerization, homogeneous polymerization, dispersion polymerization, emulsion polymerization and electrochemical synthesis of conducting polymers.

\subsubsection{Step-growth polymerization}

In this process, stepwise condensation of any functional group of the di-functional monomers can be performed. The polycondensation of the components such as polyamides (nylon), polyesters and polyurethanes is possible by using the supercritical carbon dioxide $\left(\mathrm{scCO}_{2}\right)$. The reaction firstly produces dimers, followed by the formation of larger molecules that convert it into the polymeric chains, driven by the elimination of smaller molecules under vacuum. This provides the higher kinetics of the reaction and molecular weights of the product [14]. Major problems linked with this procedure is the tedious removal of the by-products having high viscosity, it can be overcome by using the melt-phase polycondensation through supercritical carbon dioxide $\left(\mathrm{scCO}_{2}\right)$, because plasticizing effect of the carbon dioxide reduces the viscosity of melt by inducing the better stirring rate. Primarily, the supercritical carbon dioxide $\left(\mathrm{scCO}_{2}\right)$ allows the extraction of the by-products [15]. Polyurethanes and polydimethylsiloxane (PDMS) can be synthesized by using the supercritical carbon dioxide $\left(\mathrm{scCO}_{2}\right)$ as dispersant media at $60^{\circ} \mathrm{C}$ and above 200 bar pressure, ethylene glycol and tolylene-2,4-diisocyanate is used as monomers and hydroxyor isocyanate-terminated polydimethylsiloxane serve as a surfmer (Fig.2) [2]. The surfmers, also known as polymerizable surfactants, surface-active monomers, polymerizable emulsifiers, monomeric surfactants, or monomeric emulsifiers, are the largest group of reactive surfactants. The polymerizable surfactants act in emulsion polymerization both as a surfactant and as a co-monomer [16]. 


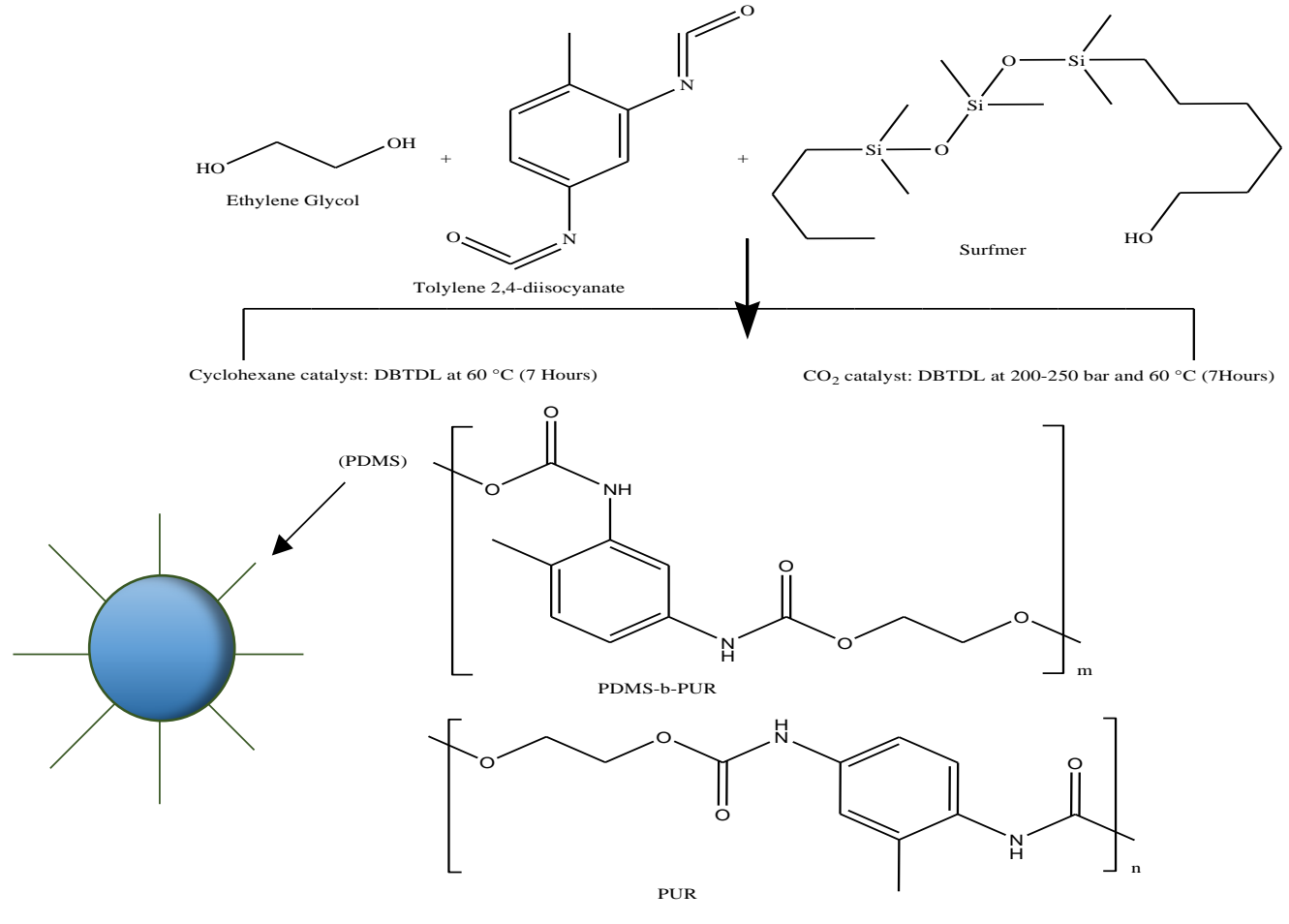

Fig. 2: Reaction between tolylene 2,4-diisocyanate and ethylene glycol in the presence of surfmer

\subsubsection{Homogeneous polymerization}

The process of homogeneous polymerization is known to use the pure homogeneous solutions of the pure monomeric reactants, as a solvent molecule. The series of completely fluorinated acrylic polymers can successfully be formed by using the non-fluorinated copolymers and fluorinated homopolymers, using homogeneous polymerization in the supercritical carbon dioxide $\left(\mathrm{scCO}_{2}\right)$. Most of the amorphous polymers are known to have the larger fractions of fluorinated acrylic monomers having molecular weight greater than 80, but are insoluble in most of the organic solvents and soluble in some chlorofluorocarbons (CFCs). The solvent properties of carbon dioxide are quite parallel to the solvent properties of fluorocarbons, such as amorphous flouropolymers and chlorofluorocarbons (CFCs) that can easily be synthesized by the homogeneous polymerization. Consequently, the carbon dioxide is the most suitable solvent for the homogeneous synthesis of flouropolymers, using cationic polymerization and free radical polymerization as mentioned below (Fig.3). Some of the fluorinated acrylate monomers like 1,1-dihydrofluorooctyl acrylate (FOA) are first synthesized by the process of polymerization and copolymerization using the vinyl hydrocarbon monomers in the presence of supercritical carbon dioxide $\left(\mathrm{scCO}_{2}\right)[14]$.

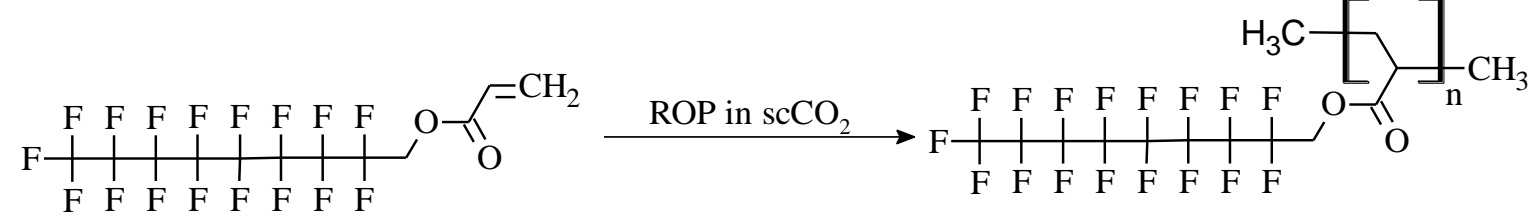

1,1-dihydroperfluorooctyl acrylate (FOA)

(PFOA)

Fig. 3: Homogenous polymerization of FOA monomer to PFOA in $\mathrm{scCO}_{2}$

\subsubsection{Electrochemical synthesis of conducting polymers}

The conducting polymers can be successfully used in the electrochemical devices, light emitting devices, and chemical and optical sensors. Many traditional methods for their synthesis include the electrochemical oxidation or chemical oxidation through the application of charge transfer agent. Conventionally, these types of procedures involve the use of many hazardous reagents, but now the use of supercritical fluids (SCFs) can give non-hazardous reaction environment. The conducting polymers such as polypyrrole and polyaniline can be successfully synthesized electrochemically using supercritical carbon dioxide which acts as a solvent. The supercritical carbon dioxide $\left(\mathrm{scCO}_{2}\right)$ and other supercritical fluids have been applied for the electrochemical production of the conductive polymers, metallized nanotube polymer composite, with their applications in the shielding of radiation and electromagnetic effects [1]. 


\subsubsection{Dispersion polymerization}

In the phenomenon of the dispersion polymerization, the polymer is synthesized by polymerizing the monomer and initiator into the carbon dioxide, using a stabilizer that stabilizes the dispersed polymer particles. This procedure converts the reaction medium from homogeneous to heterogeneous condition. The stabilizer acts by introducing the steric repulsion in between the growing particles. Nevertheless, non-fluorinated steric stabilizer can be used now, that is more advantageous in the polymerization involving the dispersion using supercritical carbon dioxide $\left(\mathrm{scCO}_{2}\right)$. Recently, the hydrocarbon block copolymers were also used as potential stabilizers, but due to the lack of solubility in the carbon dioxide, agglomeration of the polymeric particles results [17]. Interestingly, some polymers such as polyvinyl esters, polyvinyl acetate and polyvinyl pivalate were the better replacements for the conventional fluorinated surfactants [18].

\subsubsection{Emulsion polymerization}

In case of the emulsion polymerization, the mixtures of organic solvents and biphasic liquids, having large number of stabilizers are more preferably used as they tend to modify the polymeric structure after the complete polymerization. As a result of this process, the polymers of very high molecular weights are formed as they do not depend on the viscosity of reaction medium. At the completion of polymerization reaction, the elongated chains tend to remain attached with the impurity atoms, having very low concentration. The stable emulsions can easily be synthesized by using the different types of surfactants constituting the carbon dioxide phillic and carbon dioxide phobic parts that determine the nature of formed emulsion such as (i) carbon dioxide in water emulsion and (ii) water in carbon dioxide emulsion, for the polymerization reaction. In case of water in carbon dioxide emulsion system, the surfactants form micelle using the hydrophilic monomer, and they solubilized after the polymerization within aqueous phase and suspended particles form within the supercritical carbon dioxide $\left(\mathrm{scCO}_{2}\right)$ [19].

\subsection{APPLICATIONS OF POL YMER PRODUCTION AND PROCESSING USING $\mathrm{scCO}_{2}$}

The use of supercritical carbon dioxide $\left(\mathrm{scCO}_{2}\right)$ is found in the large number of commercial scale applications including (i) modifications of polymers (ii) impregnation method (iii) regular purification processes of polymers and (iv) production of particles. The schematic diagram of the applications of production of polymers in supercritical carbon dioxide $\left(\mathrm{scCO}_{2}\right)$ is shown below (Fig.4).

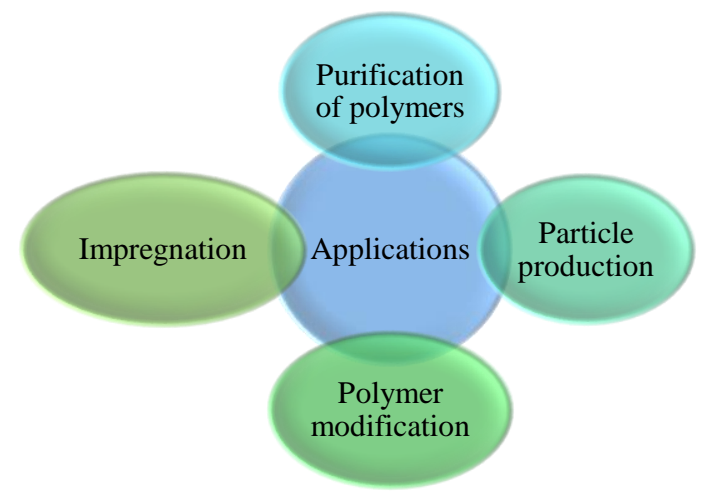

Fig.4. Applications of polymer production in $\mathrm{scCO}_{2}$

\subsubsection{Purification of polymers}

For the quantitative analysis of extracted organic compounds from the complex polymeric matrix, large number of conventional approaches has been employed during the synthesis and processing of polymers. The residual raw material and some important by-products of the process of polymerization are carefully separated from the reaction mixture. Some of the most conventional approaches for the purification of polymers include various methods such as (i) polymer dissolution method (ii) solvent intensive method and (iii) soxhlet extraction method. The supercritical carbon dioxide $\left(\mathrm{scCO}_{2}\right)$ has the ability to efficiently extract these types of by-products. In order to achieve this purpose, first of all, the polymers are swelled inside the polymerization matrix and impurities are solubilized in the supercritical carbon dioxide $\left(\mathrm{scCO}_{2}\right)$, followed by the reduction in pressure. After reducing the pressure of reaction mixture, the supercritical carbon dioxide $\left(\mathrm{scCO}_{2}\right)$ is easily diffused out of the reaction media, involving the formation of polymers.

The solvating potential of the supercritical carbon dioxide $\left(\mathrm{scCO}_{2}\right)$ is regularly monitored and slight modifications in the temperature and pressure are carefully controlled. Therefore, supercritical carbon dioxide $\left(\mathrm{scCO}_{2}\right)$ can be used in the purification of polymers after the successful synthesis in the reaction mixture [20]. Furthermore, no harmful residues are left in the reaction vessel, indicating the non-toxic nature of supercritical carbon dioxide $\left(\mathrm{scCO}_{2}\right)$. These types of reactions can easily be recycled due to the highly volatile nature of supercritical carbon dioxide $\left(\mathrm{scCO}_{2}\right)$. As compared to the various other conventional approaches, the use of preheated dry membrane of supercritical carbon dioxide $\left(\mathrm{scCO}_{2}\right)$ offers the less shrinkage and enhanced water permeability [21]. 


\subsubsection{Impregnation and supercritical dyeing}

The carbon dioxide is used as a potential solvent for the introduction of large number of metallic complexes and dye molecules in the host polymeric networks. Almost all the doping solutes act as a guest and are introduced in the complex polymeric network during the process of dyeing and impregnation of polymers. The supercritical properties of supercritical carbon dioxide $\left(\mathrm{scCO}_{2}\right)$ such as higher diffusivity, easy solvent recovery and relatively low surface tension, helps in the preparation of new and larger polymers [22]. The process of impregnation involves the absorption of liquids in the viscous polymeric networks. During the process of impregnation by the supercritical carbon dioxide $\left(\mathrm{scCO}_{2}\right)$, most of the therapeutic drugs are dissolved in the solvents, prior to the impregnation in the polymeric matrix, for the controlled delivery of bioactive ingredients. The two basic mechanisms for the infiltration of supercritical carbon dioxide $\left(\mathrm{scCO}_{2}\right)$ can be used as a potential additive on the polymeric network. In the first mechanism, the solute is solubilized in supercritical carbon dioxide $\left(\mathrm{scCO}_{2}\right)$, followed by the sudden reduction of pressure. When the pressure decreases, the supercritical carbon dioxide $\left(\mathrm{scCO}_{2}\right)$ vacates the polymeric matrix and large number of solute particles, entrapped inside the polymers. In the second process, solute is partitioned in the polymeric matrix due to relatively low solubility in supercritical carbon dioxide $\left(\mathrm{scCO}_{2}\right)$. The high affinity of solutes in the polymeric matrixes is the key factor in the dyeing process using the supercritical carbon dioxide $\left(\mathrm{scCO}_{2}\right)[23]$.

\subsubsection{Particle production}

The regular processes of the grinding and milling of the fine polymeric particles can deteriorate their physical structure and alter their chemical characteristics. Therefore, the use of supercritical carbon dioxide $\left(\mathrm{scCO}_{2}\right)$ as an anti-solvent offers the more capable approach in order to reduce their particle size and to enhance their morphological properties. By adjusting the process parameters such as (i) diameter of nozzle (ii) rate of depressurization (iii) reaction pressure and (iv) process temperature, the sizes of obtained polymeric particles can be varied. For the formation of polymeric particles, relatively high pressure is required along with the use of supercritical carbon dioxide $\left(\mathrm{scCO}_{2}\right)$ instead of the regular organic solvents, that produces the toxic wastes and undesirable solvents as a by-product. The particles having diameter in the micro-meter range can be produced by using the (i) polyester epoxy system (ii) polyester coating and (iii) low melting acrylic coatings. Inspite of using the two above mentioned processes, the polymeric particles can also be formed by the precipitation method using the rapid expansion in the presence of supercritical carbon dioxide $\left(\mathrm{scCO}_{2}\right)$ as an anti-solvent agent [24].

\subsubsection{Polymer modification}

Almost all the monomers and initiators can be dissolved in the carbon dioxide that ultimately enhances the diffusion capacity inside the complex polymeric network and can easily be modified as per the morphological features of the polymers. The grafting of some specific chemical groups inside the polymeric substrate can be performed through the number of additional reactions. The grafting of isopropyl-isocyanate on the surface of ethylene-vinyl alcohol copolymers $(\mathrm{EVOH})$ has number of advantages of the supercritical carbon dioxide $\left(\mathrm{scCO}_{2}\right)$ which ensures to provide the selective dispersion instead of the frequent chemical reactions of the monomers inside the ethylene-vinyl alcohol copolymers $(\mathrm{EVOH})$, thereby maintaining the crystalline nature of reaction medium [2].

\subsection{FACTORS AFFECTING THE POLYMERIZATION}

Number of factors is known to affect the polymerization process of the pharmaceutically and industrially valuable marketable compounds. Some of the most important factors include the (i) reaction pressure (ii) temperature of entire process and (iii) $\mathrm{pH}$ of reaction media. The schematic diagram of the factors affecting the process of polymerization is shown (Fig.5).

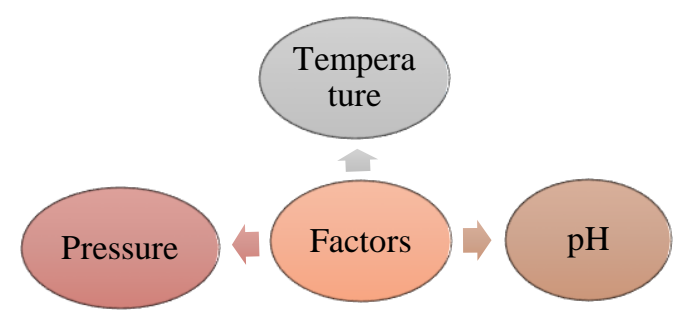

Fig. 5: Factors affecting the polymerization phenomenon

\subsubsection{Effect of $p H$}

The viscosity of the aqueous solution of synthesized polymers can increase slowly with the increase of $\mathrm{pH}$ values. Different groups of the monomers ionize by increasing the $\mathrm{pH}$ value. Similarly, the electrostatic repulsions induce the extension of chains, found in between the anions of the polymeric chains. Therefore, viscosity of the reaction mixture 
increases upto great extent, only until all the groups become ionized. The unique behaviour is shown by the siloxane modified copolymers. In the beginning of the reaction, the maximum viscosity curve of the copolymers versus $\mathrm{pH}$ is attained, that is found to be the $\mathrm{pH}=5.0$. It demonstrates that the viscosity of $2 \%$ aqueous solution of poly(acrylic acid) and various other copolymers are comparable as a function of $\mathrm{pH}$. These types of processes can also be evaluated as a consequence of hydrophobic associations among the copolymeric chains [25].

\subsubsection{Effect of pressure}

The pressure is known to have the significant effects on the final structure of complex polymeric molecules, having constant temperature and constant rate of depressurization of reaction mixture. The bulk polymeric density and mean diameter of the polymeric network tends to decrease by increasing the pressure and enhancing the density of cells. At the constant temperature value, more fluid can be dissolved by increasing the pressure, inside the polymeric network that causes the significant reduction in viscosity and enhances the extent of plasticization. The pronounced rate of plasticization indicates that the interval in between the point of vitrification and saturation pressure is also increased. Some of the key factors controlling the size of cell are the formation of more number of nuclei. As a result of increase in pressure, the overall cellular density is also increased [26].

\subsubsection{Effect of temperature}

The effects of change in temperature on the final structure of larger polymeric molecules can only be evaluated by keeping the pressure of reaction mixture constant. Through the constant rate of depressurization, the density of polymeric network decreases with the increase in temperature. When this type of reaction is carried out at the high temperature, the diffusivity of carbon dioxide is enhanced and the overall cell growth becomes faster. The interval in between the vitrification pressure and saturation pressure can also be increased that results in the longer growing periods and formation of larger cell colonies and foams, exhibiting the reduced bulk density. At the final stage, as the temperature increases, the solubility of carbon dioxide decreases in the complex network of polymers, along with the reduction in cellular density. At relatively high temperature, less fluid is dissolved in the polymeric matrix, and found to be available for the nucleation and growth of pores, forming the small number of nuclei [27].

\subsection{ANALYTICAL TECHNIQUES}

\subsection{1. ${ }^{1} \mathrm{H}$ nuclear magnetic resonance (NMR)}

The ${ }^{1} \mathrm{H}$ NMR or proton nuclear magnetic resonance is the application of nuclear magnetic resonance in NMR spectroscopy. It determines the hydrogen nuclei in the molecules of substance to determine the structure of complex analyte of interest. In samples, all the hydrogen consists of isotope ${ }^{1} \mathrm{H}$ where natural hydrogen $(\mathrm{H})$ is used. The spectra of all the molecules can be recorded in the solution and solvent protons which must not be allowed to interfere [28].

\subsubsection{Fourier transform infrared spectroscopy (FTIR)}

The functional groups of any unknown compound can be identified by using FTIR. This method also exhibits the difference in functional groups before and after the treatment. The FTIR study is also used to confirm the structure of the polymers.

\subsubsection{Differential scanning calorimetry (DSC)}

The differential scanning colorimetry is an advanced analytical technique, where the difference in amount of heat is usually evaluated to estimate the thermal degradation of analyte of interest. In this technique, the temperature difference of reference and sample is noted and measured as a function of amount of heat required. By using this technique, the melting temperature and crystallization temperature of the polymers can also be estimated.

\subsection{4. $\quad X$-ray diffraction technique (XRD)}

The $\mathrm{x}$-ray powder diffraction (XRD) is very rapid analytical technique which is used for the phase identification of crystalline materials and it also provides information on the unit cell dimensions. The XRD is used for the determination of chemical arrangement and structure of synthesized polymers [29].

\section{CONCLUSION}

The supercritical carbon dioxide $\left(\mathrm{scCO}_{2}\right)$ is a very important polymerization solvent and an effective substitute of the organic synthesis mainly because of the (i) less harmful environmental consequences (ii) cost efficient approach and (iii) energy saving processes. The use of supercritical carbon dioxide $\left(\mathrm{scCO}_{2}\right)$ also has strong influences on the physical and chemical properties of the newly synthesized polymeric molecules. The supercritical carbon dioxide $\left(\mathrm{scCO}_{2}\right)$ is used in the various polymerization techniques including the emulsion polymerization, dispersion polymerization, homogeneous polymerization and step growth polymerization. Large number of processing strategies mainly depends on the supercritical carbon dioxide $\left(\mathrm{scCO}_{2}\right)$ due to the plasticizing effects and anti-solvent properties. The faster rates 
of polymerization and variable volume reactor setups can be achieved by using and optimizing the reaction conditions in the presence of supercritical carbon dioxide $\left(\mathrm{scCO}_{2}\right)$. It is a potential alternative for the large number of non-polar and polar organic solvents, having number of applications including the (i) targeted particle production (ii) purification of organic polymeric molecules and (iii) impregnation of newly synthesized polymers. Large number of methods such as (a) fourier transform infrared spectroscopy (FTIR) (b) ${ }^{1} \mathrm{H}$ nuclear magnetic resonance spectroscopy (c) differential scanning calorimetry (DSC) and (d) x-ray diffraction technique (XRD) have been evaluated to analyse the structure and functional group arrangements of the polymer molecules. The effects of different parameters including the $\mathrm{pH}$, temperature and pressure on the rate of polymerization have also been discussed in detail. The supercritical fluids (SCFs) offer very marvellous opportunity in the research linked with the polymers and provide the high scope for the development of more promising and very sustainable processes to the polymeric industry.

\section{ACKNOWLEDGMENT}

Author is very thankful to staff of library of UAF providing assistance in literature search during compilation of this review article

\section{CONFLICTS OF INTEREST}

The authors declare no conflict of interest.

\section{REFERENCES}

1. N. Cheikhyoussef, A. Cheikhyoussef, Elsevier: 435-453. (2020).

2. P., M. Yadav, A. Agrawal, R. Alexander, S. Patel, S. Siddique S. Saraf, In: Green Sustainable Process for Chemical and Environmental Engineering and Science. Elsevier: 1-16. (2020).

3. F. Cansell, C. Aymonier, A. Loppinet-Serani, Current Opinion in Solid State and Materials Science. 7: 331 340. (2003).

4. Ž. Knez, M. Pantić, D. Cör, Z. Novak, M. K. Hrnčič, Chemical Engineering and Processing-Process Intensification: 107532. (2019).

5. O. R. Davies, A. L. Lewis, M. J. Whitaker, H. Tai, K. M. Shakesheff and S. M. Howdle, Advanced drug delivery reviews. 60: 373-387. (2008).

6. A. Alzahrani, D. Zhou, R. P. Kuchel, P. B. Zetterlund and F. Aldabbagh, Polymer Chemistry. 10: 2658-2665. (2019).

7. J. Xie, D. Liu, H. Yan, G. Xie and S. K. Boetcher, International Journal of Heat and Mass Transfer. 149: 119233. (2020).

8. S. Y. Tuzova, A. Y. Nikolaev, L. Nikitin, A. Pestrikova and I. Y. Gorbunova. Russian Journal of Inorganic Chemistry. 60: 724-728. (2015).

9. T. Demina, A. Gilman and A. Zelenetskii, High Energy Chemistry. 51: 302-314. (2017).

10. J. T. Boock, A. J. Freedman, G. A. Tompsett, S. K. Muse, A. J. Allen, L. A. Jackson, B. Castro-Dominguez, M. T. Timko, K. L. Prather and J. R. Thompson. Nature communications. 10: 587. (2019).

11. M. Bhamidipati, A. M. Scurto and M. S. Detamore. Tissue Engineering Part B: Reviews. 19: 221-232. (2013).

12. R. Viveiros, K. Karim, S. Piletsky, W. Heggie and T. Casimiro. Journal of cleaner production. 168: 1025-1031. (2017).

13. E. Kiran, The Journal of Supercritical Fluids. 110: 126-153. (2016).

14. C. Boyère, C. Jérôme and A. Debuigne. European Polymer Journal. 61: 45-63. (2014).

15. E. Ramsey, S. Qiubai, Z. Zhang, C. Zhang and G. Wei. Journal of Environmental Sciences. 21: 720-726. (2009).

16. M. Kaczorowski, G. Rokicki. Polimery. 61: 747--757. (2016).

17. M. J. Derry, L. A. Fielding and S. P. Armes, Progress in Polymer Science. 52: 1-18. (2016).

18. M. Altarsha, F. Ingrosso and M. F. Ruiz-Lopez, ChemPhysChem. 13: 3397-3403. (2012).

19. T. M. Attard, A. J. Hunt, In: Supercritical and Other High-pressure Solvent Systems. 340-373. (2018).

20. C. S. C. Sasaki, A. T. Quitain, T. Kida and N. Taniyama, The Journal of Supercritical Fluids. 146: 23-29. (2019).

21. S. Cardea, E. Reverchon, Multidisciplinary Digital Publishing Institute. 1551. (2019).

22. W. Zhu, Y. Fan, C. Zhang, C. Cai, J. Long and M. Shi, Textile Research Journal. 89: 3475-3483. (2019).

23. M.T. Abate, A. Ferri, J. Guan, G. Chen, V. Nierstrasz, Advanced Supercritical Fluids Technologies. (2019).

24. J. Patra, H.-C. Chen, C.-H. Yang, C.-T. Hsieh, C.-Y. Su and J.-K. Chang. Nano Energy. 28: 124-134. (2016).

25. Z.-W. Kang, R. K. Kankala, B.-Q. Chen, C.-P. Fu, S.-B. Wang and A.-Z. Chen. ACS Applied Materials \& Interfaces. (2019).

26. M. L. Goñi, N. A. Gañán, J. M. Herrera, M. C. Strumia, A. E. Andreatta and R. E. Martini. The Journal of Supercritical Fluids. 122: 18-26. (2017). 
27. I. Tsivintzelis, A. G. Angelopoulou and C. Panayiotou, Polymer. 48: 5928-5939. . (2007).

28. H. Kamali, R. Mollaee, E. Khodaverdi, F. Hadizadeh and G. H. Zohuri. The Journal of Supercritical Fluids. 145: 133-139. (2019).

29. N. M. Belomoina, E. G. Bulycheva, I. V. Elmanovich, M. I. Buzin, R. S. Begunov, I. S. Chaschin and L. A. Wasserman, The Journal of Supercritical Fluids. 148: 148-154. (2019).

Received: $18^{\text {th }}$ January, 2021

Accepted: 26 $^{\text {th }}$ April, 2021 